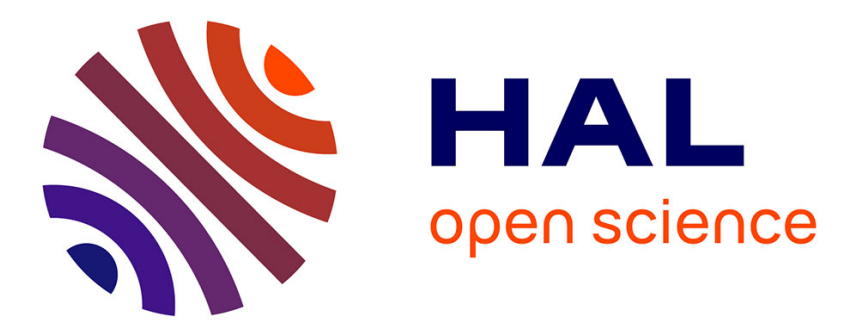

\title{
Evidence of reproductive cost in the triphasic life history of the red alga Gracilaria chilensis (Gracilariales, Rhodophyta)
}

Marie-Laure Guillemin, Paula Valenzuela, Juan Diego Gaitán-Espitia, Christophe Destombe

\section{To cite this version:}

Marie-Laure Guillemin, Paula Valenzuela, Juan Diego Gaitán-Espitia, Christophe Destombe. Evidence of reproductive cost in the triphasic life history of the red alga Gracilaria chilensis (Gracilariales, Rhodophyta). Journal of Applied Phycology, 2013, 26 (1), pp.569-575. 10.1007/s10811-013-0072-x . hal-01140019

\section{HAL Id: hal-01140019 \\ https://hal.science/hal-01140019}

Submitted on 17 Apr 2015

HAL is a multi-disciplinary open access archive for the deposit and dissemination of scientific research documents, whether they are published or not. The documents may come from teaching and research institutions in France or abroad, or from public or private research centers.
L'archive ouverte pluridisciplinaire HAL, est destinée au dépôt et à la diffusion de documents scientifiques de niveau recherche, publiés ou non, émanant des établissements d'enseignement et de recherche français ou étrangers, des laboratoires publics ou privés. 
1 Evidence of reproductive cost in the triphasic life history of the red alga Gracilaria

2 chilensis (Gracilariales, Rhodophyta).

4 Marie Laure Guillemin ${ }^{1,2 a}$, Paula Valenzuela ${ }^{1,2}$, Juan Diego Gaitán-Espitia ${ }^{1,2}$ \&

5 Christophe Destombe ${ }^{3,4}$

6

$7 \quad{ }^{1}$ Instituto de Ciencias Ambientales y Evolutivas, Universidad Austral de Chile, Casilla

8567 Valdivia, Chile.

$9 \quad 2$ Laboratorio Costero Calfuco, Instituto de Biología Marina "Jürgen Winter"

10 Universidad Austral de Chile, Casilla 567, Valdivia, Chile

$11{ }^{3}$ UPMC, UMR 7144, Adaptation \& Diversité en Milieu Marin, Equipe “BEDIM”,

12 Station Biologique, Place Georges Teissier, F-29682 Roscoff Cedex, France.

$13{ }^{4}$ CNRS, UMR 7144, Adaptation \& Diversité en Milieu Marin, Equipe “BEDIM”, Station

14 Biologique, Place Georges Teissier, F-29682 Roscoff Cedex, France.

$15{ }^{a}$ Corresponding author: Marie Laure Guillemin. Instituto de Ciencias Ambientales y

16 Evolutivas, Facultad de Ciencias, Universidad Austral de Chile, Casilla 567 Valdivia,

17 Chile. Phone: +56 63 221704; fax: +56 63 221344. Email address:

18 marielaure.guillemin@gmail.com

19

20 


\section{ABSTRACT}

22 The extent of changes in basic physiological and demographic traits associated with

23 reproduction was investigated in the highly cultivated haploid-diploid red alga,

24 Gracilaria chilensis. Sixty individuals bearing vegetative and reproductive fronds

25 collected in the natural population of Niebla ( $\left.39^{\circ} 52^{\prime} \mathrm{S}, 73^{\circ} 23^{\prime} \mathrm{W}\right)$, in Chile, were

26 cultivated under control culture conditions. Our results demonstrated that vegetative

27 fronds have a higher survival rate and a better growth rate than reproductive ones

28 whatever the type of individual analyzed (male gametophyte, female gametophyte and

29 tetrasporophyte). Moreover, the reproductive fronds clearly showed a decrease in

30 photosynthetic activity compared to non-reproductive ones. In males and

31 tetrasporophytes the photosynthetic reduction in reproductive individual could be

32 explained by a physical effect of reproductive structure development as well as spores

33 release, disrupting the continuity of the photosynthetic cortical tissues. Translocation of

34 photoassimilates from nearby vegetative tissue or on the previous accumulation of

35 photosynthetic products seems to be a prerequisite for reproductive structure

36 development in this species. Altogether, these results document for the first time in $G$.

37 chilensis that reproduction has a strong physiological effect on male, female and

38 tetrasporophyte fronds. This trade-off between reproduction, growth and survival, suggest

39 the existence of reproductive costs in the life history of G. chilensis. 


\section{Introduction}

43 The existence of reproductive cost has been demonstrated in various animals

44 (Reznick et al. 2000) and plants (Obeso 2002). The concept of reproductive cost,

45 developed by Fisher (1930) and Harper (1967), provides the conceptual framework of the

46 theory of resource allocation (for review see Bazzaz et al. 2000). This theory predicts the

47 existence of a resource trade-off between reproduction, growth and survival, assuming

48 that reproductive effort imposes a cost on an organism in terms of reduced growth or

49 lower survival (Fisher 1930; Bell 1984; Stearns 1992). Consequently, the study of

50 resource investment in reproduction constitutes a crucial parameter in the understanding

51 of life history strategies of any given species (Harper 1967). According to Bell (1984),

52 reproductive cost is a necessary condition for the optimization of life histories. Indeed,

53 the evolution of life history is constrained by the presence of trade-offs among some of

54 the traits that contribute to fitness (Stearns 1992).

55 In terrestrial plants, such trade-offs have been demonstrated experimentally in

56 limited resources conditions either between sexual reproduction and vegetative growth

57 (Obeso 2002) or between reproduction and survival rate (Rameau and Gouyon 1991). In

58 dioecious plants, studies have shown clear differences in responses among sexes, with

59 females investing more carbon, nitrogen, and other resources in reproduction than males

60 (Obeso 2002). This difference in reproductive effort has been mainly related to the

61 production of seeds, fruits and associated structures (Ashman 1994) and has often been

62 linked with differences in photosynthetic performance (Wheelwright and Logan 2004).

63 In seaweed, cost of reproduction remains poorly documented (for review see De

64 Wreede and Klinger 1990) and has been mainly addressed in Phaeophyceae species in 
65 which reproductive organs are clearly differentiated (e.g. receptacles and sporophylles)

66 (Vernet and Harper 1980; McCourt 1985; Ang 1992; Mathieson and Guo 1992; Åberg

67 1996; Zou et al. 2011). While a reproductive cost, like growth reduction or decrease of

68 survival rate, has been observed in various fucoids (McCourt 1985; Ang 1992; Mathieson

69 and Guo 1992; Åberg 1996; Chu et al. 2011), the existence of resource trade-off in algae

70 has been discussed, because reproductive organs are normally pigmented and potentially

71 able to photosynthesis before the release of spores or gametes (De Wreede and Klinger

72 1990). However, the reproductive period coincide generally with the end of growth and

73 can be followed by the senescence and the death of the parental thallus (Zou et al. 2006).

74 In Rhodophyta species, resource trade-off between reproduction and vegetative

75 growth was more difficult to assess because reproductive organs are generally embedded

76 in the cortical tissues of the photosynthetic thallus except for female individuals showing

77 a parasitic-like development of cystocarp on the female thallus after fertilization

78 (Hommersand and Fredericq 1995). In Gracilaria chilensis and G. domingensis, it has

79 been shown that vegetative growth of female gametophyte decreases after fertilization

80 during the development of cystocarps (Santelices and Varela 1995; Guimarães et al.

81 1999), suggesting that resources were limited. Similarly, the results obtained in the three

82 Ceramiacean species, Antithamnion nipponicum, Ceramium boydenii and C. japonicum,

83 demonstrated that the number and size of spores released depends on the length of the

84 vegetative branch on which cystocarps were produced (Kamiya and Kawai 2002). All

85 these results support the existence of a high photosynthetic investment in reproductive

86 structures of female gametophyte in Rhodophyta. In male and tetrasporophyte

87 individuals, the influence of reproductive structure on survival and growth was rarely 
88 assed (but see Santelices and Varela 1995). In these two types of individual, the

89 reproductive structure derives from cortical tissues, and the dual role of the thallus (i.e.,

90 photosynthesis and reproduction) raises questions regarding the potential trade-offs

91 involved in the maintenance of these two functions. Thornber (2006) hypothesized that

92 haploid (male and female gametophytes) and diploid (tetrasporophytes) individuals could

93 differ in vegetative growth, survival and respective investment in reproductive structures.

94 The aim of this study was to analyze the ecophysiological outcomes of the

95 development of reproductive structures in the red seaweed Gracilaria chilensis for the

96 three types of individuals (males, females and tetrasporophytes). This species is the most

97 commercially important agarophyte in Chile (Buschmann et al. 2001). We studied the

98 influence of the reproductive status on survival and growth rates as well as basic

99 physiological parameters of interest (i.e., respiration rate, net primary production and

100 pigment content) by comparing reproductively and vegetative fronds of male

101 gametophyte, female gametophyte and tetrasporophyte individuals.

\section{Materials and methods}

\section{Species under study}

105 Gracilaria chilensis exhibits a typical Polysiphonia-type life cycle with two free-

106 living isomorphic generations. Meiosis occurs in the reproductive diploid individuals

107 (tetrasporophytes) to produce haploid spores (tetraspores). When liberated, tetraspores

108 attach to the substratum, develop perennial holdfasts, and grow into haploid dioecious

109 gametophytic males and females. Male gametes are liberated in the water column,

110 whereas female gametes are retained on the female thallus. After fertilization the 
111 carposporophyte (cystocarp) develops on the female haploid plant and the zygote

112 undergoes successive mitoses to produce a gonimoblast from which many thousands of

113 identical diploid spores are formed. When liberated, carpospores attached to the

114 substratum develop into perennial holdfasts, subsequently growing into a tetrasporophyte,

115 completing the complex life cycle. In Chile, natural populations formed by individuals

116 growing from a perennial holdfast and attached to the rocky substratum are encountered

117 between Coquimbo and Raul Marin Balmaceda $\left(30^{\circ} \mathrm{S}\right.$ and $45^{\circ} \mathrm{S}$; Bird et al., 1986). As

118 vegetative fronds share the same morphology, phase and sex of individuals can be

119 recognized only during the reproductive period.

120

\section{Laboratory experimental design}

122 Individuals of G. chilensis were collected at low tide in the natural population of Niebla

$123\left(39^{\circ} 52^{\prime} \mathrm{S}, 73^{\circ} 23^{\prime} \mathrm{W}\right.$, Region XIV, Chile) in March 2010. The type of individuals was

124 identified according to their reproductive structures (tetrasporangia for tetrasporophytes,

125 spermatangia for males and cystocarps for fertilized females), using a binocular

126 microscope (SMZ-10; Nikon Co., Tokyo, Japan) (Guillemin et al. 2008). Even if

127 reproductive individuals of $G$. chilensis could be encountered all year round (Meneses,

128 1996), a three-year survey of the Niebla population has shown that the highest percentage

129 of reproductive individuals was encountered during summer (December to April) with at

130 least $85 \%$ of reproductive individuals (Guillemin M-L. unpublished data). Twenty

131 tetrasporophytes, 20 females and 20 males, were sampled and cleaned of epiphytes. For

132 each individual, two grams of fresh weight of vegetative fronds and two grams of fresh

133 weight of reproductive fronds were selected to obtain six groups of fronds (vegetative 
134 females, males and tetrasporophytes; and reproductive females, males and

135 tetrasporophytes). Following the criteria suggested by Guzmán-Urióstegui et al. (2002),

136 we selected for experimental analyses only the healthy fronds with no damage (i.e.,

137 alteration of the cortical tissue) or discoloration. Only fronds with early stages of

138 reproductive structures where selected to form the three groups of reproductive fronds.

139 The fronds were incubated during two weeks in $1 \mathrm{~L}$ Erlenmeyer flask (Schott Duran,

140 Elmsford, NY, USA) of culture medium (Modified SFC culture medium, Correa and

141 McLachlan 1991) aerated with ambient air under controlled photoperiod (12:12 h L:D),

142 photon flux density $\left(60 \mu \mathrm{mol} \mathrm{m}^{-2} \mathrm{~s}^{-1}\right)$, temperature $\left(15 \pm 1^{\circ} \mathrm{C}\right)$ and salinity (35 PSU). An

143 important spore released was observed during the first $48 \mathrm{~h}$ for both tetrasporophytes and

144 females. However, a continuous and low spore shading was observed until the end of the

145 experiment for these two types of individuals (spores not counted during our study).

146 Basic physiological parameters and survival rate and growth rates of vegetative fronds

147 were measured on fronds without visible reproductive structure under binocular

148 microscope observation. For reproductive fronds, measures were performed on male and

149 tetrasporophyte fronds showing reproductive structures and, on female fronds, with at

150 least two cystocarps per centimeter. Male and tetrasporophyte reproductive thalli selected

151 presented a continuous and homogenous cover of reproductive structures (100\%

152 covering).

153 Pigments content

154 Chlorophyll $a(\mathrm{Chl} a)$ was extracted from $10-15 \mathrm{mg}$ fresh weight samples in N, N-

155 dimethylformamide (DMF) following the protocols of Gómez et al (2005). Absorbance

156 values of the supernatant were measured using a spectrophotometer (SUV-2120; Scinco 
157 Co., Ltd., Seoul, Korea). Chl $a$ concentration were estimated by the equation of Inskeep

158 and Bloom (1985). The phycobilins were extracted from $\sim 50 \mathrm{mg}$ fresh weight samples in

$1590.1 \mathrm{M}$ phosphate buffer $(\mathrm{pH}=6.5)$. After centrifugation ( $30 \mathrm{~min}$ at ca. $4500 \mathrm{xg}$ ) the

160 concentrations of phycoerythrin (PE) and phycocyanin (PC) were determined

161 spectrophotometrically (SUV-2120; Scinco Co., Ltd., Seoul, Korea) using the equation of

162 Beer and Eshel (1985). For each pigment concentration measurement performed, eight

163 samples of the six frond groups were selected randomly.

165 Metabolic rates and primary productivity

166 Net Primary Productivity (NPP) and Respiration (R) were measured using the

167 light and dark bottles methodology described in Howarth and Michaels (2000). Fresh

168 fronds of $0.1 \pm 0.02 \mathrm{~g}$ were placed in Falcon tubes of $50 \mathrm{~mL}$ (Becton Dickinson, Cowley,

169 Oxford, UK) filled with filtered seawater sterilized with UV light (QL-40; Rainbow

170 Lifegard; El Monte, California, USA) and kept in a temperature- and light-controlled

171 incubation chamber $\left(60 \mu \mathrm{mol} \mathrm{m}{ }^{-2} \mathrm{~s}^{-1}\right.$ and $\left.15 \pm 1^{\circ} \mathrm{C}\right)$ for twelve hours. Initial and final

172 dissolved $\mathrm{O}_{2}$ concentrations were estimated using an YSI 550A oxymeter (YSI Inc.,

173 Yellow Springs, Ohio, USA). No blank correction was applied since oxygen values in

174 light and dark control bottles remained constant. All oxygen values $\left(\mathrm{mg} \mathrm{O}_{2} \mathrm{~L}^{-1} \mathrm{~h}^{-1}\right)$ were

175 converted into carbon values $\left(\mathrm{mg} \mathrm{C} \mathrm{L}^{-1} \mathrm{~h}^{-1}\right)$ by using a factor of $0.375 / \mathrm{PQ}$ (i.e.,

176 photosynthetic quotient). The PQ value was taken as 1 and expressed as a fresh weight

177 basis. Eight replicate measurements were taken for each of the six groups of fronds. After

178 incubation, the algae from the respective bottles were dried at $60^{\circ} \mathrm{C}$ until a constant

179 weight was reached. 


\section{Survival and growth}

182 Fifty frond segments (without apex), $1 \mathrm{~cm}$ in length, were excised from each

183 group of fronds (vegetative and reproductive male, female and tetrasporophytes).

184 Separately for each group of fronds, ten segments were randomly selected and placed into

185 a $50 \mathrm{~mL}$ culture flask (Orange Scientific, Braine-L'Alleud, Belgium) with filtered

186 seawater without aeration and under low light intensity of $20 \mu \mathrm{mol} \mathrm{m}^{-2} \mathrm{~s}^{-1}$ (5 replicates).

187 Filtered seawater was changed weekly and segments were cleaned using a soft brush.

188 After 50 days, the survival rate was estimated by counting the number of healthy

189 segments (i.e., highly pigmented) and was expressed as a percentage of the original

190 number of segments at the beginning of the experiment. After 60 days, all the bleached

191 fronds fragments had died. The growth rate was estimated after 50 days by measuring the

192 number of new tips formed along the $1 \mathrm{~cm}$ length frond segment.

193

194 Data analysis

195 Physiological parameters of interest, survival and growth estimated under

196 laboratory conditions were compared using a two-way analysis of variance (ANOVA)

197 and Tukey's Honestly Significant Difference (HSD) tests (STATISTICA 7.0, StatSoft,

198 Tulsa, Oklahoma, USA). The type of individual (female, male and tetrasporophyte) and

199 the reproductive status of the fronds (vegetative or reproductive) were used as fixed

200 factors. ANOVA assumptions (homogeneity of variance and normal distribution) were

201 examined using Cochran and Kolmogorov-Smirnov tests respectively. Transformations 
202 preceded the analyses when needed $\left(\log _{10}(x+1)\right.$ for all three pigment concentrations and

$203 \operatorname{Arc} \operatorname{Sen} \sqrt{ }(\mathrm{x} / 100)$ for the survival rate).

\section{Results}

There was a significant interaction between the type of individual (female

207 gametophyte, male gametophyte and tetrasporophyte) and the reproductive status of the 208 frond (vegetative or reproductive) with respect to the concentration of phycoerythrin

209 (PE), net productivity, respiration and growth rates (Table 1). Reproductive females

210 (showing cystocarps) presented the lowest values of pigment content, net productivity

211 and respiration rate of all the fronds measured (Figure 1).

212 The reproductive status of the frond in G. chilensis strongly affects all the seven 213 ecophysiological measurements performed during our study $(p<0.001$, ANOVA Table

214 1, Figure 1). Regardless of sex or phase, vegetative fronds were characterized by a higher 215 pigment content, net productivity, survival and growth rates, than reproductive fronds

216 (Figure 1). Concentration of $\mathrm{Chl}$ a and $\mathrm{PE}$ were 1.2 to 4.5 times greater in vegetative

217 fronds than in reproductive ones (Figure 1A and B). Net productivity for vegetative

218 fronds was almost twice that of reproductive fronds for all three individual types (Tukey

219 HSD $p<0.05$, Figure 1D). On the other hand, the respiration rates were roughly similar

220 for all groups of fronds, with the exception of reproductive females, which presented a

221 reduction in the respiration rate (Figure 1E). Striking differences between vegetative and

222 reproductive fronds were observed for survival and growth rates. Indeed, after 50 days,

223 whereas male and female reproductive gametophytes segments had not generated new

224 apex, vegetative segments of $1 \mathrm{~cm}$ length (whatever the sex or phase) have generated 
225 approximately two new apices (Figure $1 \mathrm{~F}$ and $\mathrm{G}$ ). The most conspicuous differences

226 between reproductive and vegetative fronds were observed in female gametophytes and

227 the differences were significant for all the seven measures (Tukey HSD $p<0.05$, Figure

$2281)$

229 There were no consistent differences between the three types of individual except

230 for the phycobilin concentrations (PC), the net productivity and respiration rate (ANOVA

231 Table1). PE and PC were slightly higher in tetrasporophytes than in gametophytes, and

232 the lowest net productivity and respiration rate was seen in female gametophytes

233 (Figure1).

235 Discussion

236 The results of this study indicate that (1) vegetative fronds of Gracilaria chilensis

237 from the natural population of Niebla (Chile) have a higher survival rate and a better

238 growth rate than reproductive ones and (2) the reproductive fronds clearly show a clear

239 decrease in photosynthetic activity compared to non-reproductive fronds.

240 Previous studies in Rhodophyta species demonstrated the effect of reproduction

241 on the photosynthetic activity, such as Gelidiella acerosa (Ganzon-Fortes 1999),

242 Schottera nicaeensis (Perrone and Felicini 1988) and Porphyra yezoensis (Yang et al.

243 2012). These authors suggested that development of new reproductive structures depends

244 on translocation of photoassimilates from nearby vegetative tissue, or on the previous

245 accumulation of photosynthetic products. Yang et al. (2012) demonstrated that complete

246 maturation of the spermatia in $P$. yezoensis was determined by photosynthetic activity at

247 the beginning of the spermatangial development (i.e. the four-cell stage), while in the 
248 Chlorophyta Ulva prolifera, the formation of the mature sporangia depended directly on

249 the thallus accumulation of photosynthetic products (Gao et al. 2010). In the red algae

250 Gracilaria cornea, Guzmán-Urióstegui et al. (2002) pointed out the importance of

251 nutrient supply in the development of cystocarps, and Kamiya and Kawai (2002)

252 demonstrated in Ceramiales species that female reproductive effort depends on the length

253 of the vegetative branch where cystocarps are produced. The dependence of reproductive

254 structure upon nearby vegetative tissues in algae are generally associated to (i) a positive

255 correlation between plant size and fecundity (De Wreede and Klinger 1990; Åberg 1992;

256 Mathieson and Guo 1992; Pfister 1992; Åberg 1996; Zou et al. 2006) and (ii) the

257 existence of a threshold size necessary to achieve reproductive maturity (Gómez and

258 Westermeier 1991; Dyck and De Wreede 2006).

259 Interestingly, in our study, cystocarps, spermatangia and sporangia development

260 was concomitant to a reduction of photosynthetic rate. This was usually associated to a

261 slower growth rate and a higher mortality rate of reproductive fronds in comparison to

262 vegetative fronds. We can hypothesize that the lower net productivity observed in

263 reproductive fronds of G. chilensis is directly linked to lower pigment concentration as

264 suggested by Yokoya et al. (2007). In Gracilaria, development of reproductive organs as

265 well as the release of tetraspores borne in cortical tissue could affect directly the

266 photosynthetic activity, decreasing the pigment concentration. The negative effect of

267 carposporophyte (cystocarp) on female growth rate has been reported previously in

268 different Gracilaria species (G. sjoestedtii: Zhang and van der Meer 1988; G. chilensis:

269 Santelices and Varela 1995; G. domingensis: Guimarães et al. 1999). These results

270 suggest that the development of carposporophyte depend nutritionally on the female 
271 gametophyte (Hommersand and Fredericq 1995). Similar relationship showing a negative

272 trade-off between gametophyte growth rate and sporophyte production were also

273 observed in some bryophytes (Bisang and Ehrlen 2002; Rydgren and Økland 2003). Our

274 results corroborate previous studies on G. chilensis showing that the reproductive stages

275 have lower growth rate compared to the vegetative stages (Santelices and Varela 1995,

276 Halling et al. 2005) and suggest that reduce growth rate is due to extra energy costs for

277 producing gametes and spores (Kain and Destombe 1995).

278 Generally, the existence of long-term demographic effects of current reproduction

279 on subsequent mortality, growth, or reproduction has remained somewhat unclear in

280 algae, as incongruent results have been reported (De Wreede and Klinger 1990; Ang

281 1992; Dyck and De Wreede 2006). Low reproductive costs were suggested since

282 reproductive structures are potentially capable of photosynthesis (Santelices 1990).

283 Moreover, it has been hypothesized that the comparatively low cost of reproductive

284 structures in relation to the overall energy budget of the plant might minimize the cost of

285 reproduction in algae. In fucoid species, Vernet and Harper (1980) estimated that a very

286 low proportion of body weight was invested in gamete production $(<0.4 \%$ for female

287 gametes and $<0.02 \%$ for male gametes). Pfister (1992), suggested that plastic or

288 compensatory responses to the environment may minimize reproduction cost on kelps,

289 and Ang (1992) argued that the failure to detect cost of reproduction with respect to

290 mortality and longevity in F. distichus may be due to the modular nature of the plants,

291 where cost occurs at the level of the modules (branches or fronds) rather than at the level

292 of the whole plant (individual). In fact, in G. chilensis, Santelices and Varela (1995) have

293 proposed that the negative impact of reproductive structures in female (i.e. cystocarps) 
294 could be highly localized. Even though the long-term cost of reproduction at the

295 individual level was not measured in our study, the lower growth and survival of

296 reproductive fronds may have a strong impact on individual fitness. In short-lived

297 seaweeds (or semelparous), release of gametes or spores usually initiates the degradation

298 of the photosynthetic tissues and bouts of sexual reproduction have a clear negative

299 impact on local algal abundance (Clifton and Clifton 1999; Sánchez et al. 2003). In

300 perennial species (or iteroparous), reproduction is generally delayed and depends on the

301 individual size (Åberg, 1992). While fronds constitute the primary photosynthesis organ

302 and only seasonally bear reproductive structure, spores production and individual volume

303 are inextricably linked in G. gracilis (Engel et al. 2001). In G. chilensis, reproductive cost

304 could have a higher demographic impact in estuaries, where populations reproduce

305 mostly by vegetative fragmentation of fronds than in rocky shore, where individuals are

306 fixed by a perennial holdfast and reproduce solely by spores (Guillemin et al. 2008).

307 In conclusion, the physiological and demographic parameters analyzed in this

308 study allowed the exploration of reproductive cost in red haploid-diploid seaweeds. The

309 results revealed the existence of short-term reproductive cost in G. chilensis whatever the

310 type of individual studied (male gametophyte, female gametophyte and tetrasporophyte),

311 providing valuable insight into demographic processes at a local scale. In fact, our results

312 demonstrated that vegetative fronds have a higher survival rate and a better growth rate

313 than reproductive ones. These findings could have useful implications in the management

314 and farming practices of G. chilensis. Nevertheless, there is a need to carry out new

315 experimental approach at the population level to estimate the impact of reproduction on

316 individual survival in different local ecological environments, such as muddy or rocky 
317 shore. Similarly, since ecological differences have been reported in this species

318 (Santelices and Ugarte, 1990), it is important to understand to what extend environmental

319 variation can influence changes in the energy allocation and trade-offs between

320 reproduction, growth and survival across the geographical range of distribution of $G$.

321 chilensis and future studies should be performed in natural populations located in other

322 regions in order to generalized our results.

323

\section{Acknowledgments}

325 We thank P. Antileo and K. Contreras for their technical assistance in algae maintenance;

326 I. Gómez, M. Orostegui and C. Rosas (Inst. De Ciencias Marinas y Limnológicas,

327 Universidad Austral de Chile) for providing their expertise and facilities for pigment

328 analyses; S. Woelfl (Inst. De Ciencias Marinas y Limnológicas, Universidad Austral de

329 Chile) for facilitating us access to the oxymeter. JDGE acknowledges support provided

330 by a Conicyt Doctoral fellowship. MLG was supported by FONDECYT grant $\mathrm{N}^{\circ}$

3311090360.

332

\section{References}

334 Åberg P (1992) A demographic study of two populations of the seaweed Ascophyllum

335 nodosum in stochastic environment. Ecology 73:1473-1487

336 Åberg P (1996) Patterns of reproductive effort in the brown alga Ascophyllum nodosum.

337 Mar Ecol Prog Ser 138:199-207

338 Ang PO (1992) Cost of reproduction in Fucus distichus. Mar Ecol Prog Ser 28:25-35 
339 Ashman T (1994) A dynamic perspective on the physiological cost of reproduction in

340 plants. Am Nat 144:300-316

341 Bazzaz FA, Ackerly DD, Reekie EG (2000) Reproductive allocation in plants. In: Fenner

$342 \mathrm{M}$ (ed) Seeds: the ecology of regeneration in plant communities. CABI Publishing,

343 Wallingford, pp 1-30

344 Beer S, Eshel A (1985) Determining phycoerythrin and phycocyanin concentrations in

345 aquaeous crude extracts of red algae. Aust J Mar Fresh Res 36:785-792

346 Bell G (1984) Measuring the cost of reproduction. 1. The correlation structure of the life

347 table of a plankton rotifer. Evolution 38:300-313

348 Bird CJ, McLachlan J (1986) The effect of salinity on distribution of species of

349 Gracilaria Grev. (Rhodophyta, Gigartianles): an experimental assessment. Bot Mar

$350 \quad 29: 231-238$

351 Bisang I, Ehrlén J (2002) Reproductive effort and cost of sexual reproduction in female

352 Dicranum polysetum. Bryologist 105:384-397

353 Buschmann AH, Correa JA, Westermeier R, Hernandez-Gonzalez MDC, Norambuena R

354 (2001) Red algal farming in Chile: a review. Aquaculture 194:203-20.

355 Chu S, Zhang Q, Liu S, Zhang S, Tang Y, Lu Z, Yu Y (2011) Trade-off between

356 vegetative regeneration and sexual reproduction of Sargassum thunbergii. Hydrobiologia

$357 \quad 678: 127-135$

358 Clifton KE, Clifton LM (1999) The phenology of sexual reproduction by green algae

359 (Bryopsidales) on Caribbean coral reefs. J Phycol 35:24-34.

360 Correa JA, McLachlan JL (1991) Endophytic algae of Chondrus crispus (Rhodophyta).

361 III. Host specificity. J Phycol 27:448-459 
363 De Wreede R, Klinger T (1990) Reproductive strategies in algae. In: Lovett-Doust J,

364 Lovett-Doust L (eds) Plant reproductive ecology: patterns and strategies. Oxford

365 University Press Inc, New York, pp 267-284

366 Dyck LJ, DeWreede RE (2006) Reproduction and survival in Mazzaella splendens

367 (Gigartinales Rodophyta). Phycologia 45:302-310

368 Engel C, Åberg P, Gaggiotti O, Destombe C, and Valero M (2001) Population dynamics

369 and stage structure in a haploid-diploid red seaweed, Gracilaria gracilis. J. Ecology 89:

$370 \quad 436-450$.

371 Fisher RA (1930) The Genetical Theory of Natural Selection. Claredon Press, Oxford.

372 Ganzon-Fortes ET (1999) Photosynthetic and respiratory responses of the agarophyte

373 Gelidiella acerosa collected from tidepool, intertidal and subtidal habitats. Hydrobiologia

$374 \quad 398 / 399: 321-328$

375 Gao S, Chen XY, Yi QQ, Wang GC, Pan GH, Lin AP, Peng G (2010) A strategy for the

376 proliferation of Ulva prolifera, main causative species of green tides, with formation of

377 sporangia by fragmentation. PLoS ONE 5:e8571.

378 Gómez I, Figueroa F, Huovin P, Ulloa N, Morales V (2005) Photosynthesis of the red

379 alga Gracilaria chilensis under natural solar radiation in an estuary in southern Chile.

380 Aquaculture 244:369-382

381 Gómez IM, Westermeier RC (1991) Frond regrowth from basal disc in Iridaea

382 laminarioides (Rhodophyta, Gigartinales) at Mehuín, southern Chile. Mar Ecol Prog Ser

$383 \quad 73: 83-91$ 
384 Guillemin ML, Faugeron S, Destombe C, Viard F, Correa JA, Valero M (2008) Genetic

385 variation in wild and cultivated populations of the haploid-diploid red alga Gracilaria

386 chilensis: how farming practices favour asexual reproduction and heterozygosity.

387 Evolution 62:1500-1519

388 Guimarães M, Plastino E, Oliveira E (1999) Life history, reproduction and growth of

389 Gracilaria domingensis (Graciliariales, Rhodophyta) from Brazil. Bot Mar 42:481-486

390 Guzmán-Urióstegui A, García-Jiménez P, Marián FD, Robledo D, Robaina RR (2002)

391 Polyamines influence maturation in reproductive structures of Gracilaria cornea

392 (Gracilariales, Rhodophyta). J Phycol 38:1169-75

393 Halling C, Aroca G, Cifuentes M, Buschmann A, Troell M (2005) Comparison of spore

394 inoculated and vegetative propagated cultivation methods of Gracilaria chilensis in an

395 integrated seaweed and fish cage culture. Aquacult Int 13:409-422.

396 Harper JL(1967). A Darwinian approach to plant ecology. J Ecol 55:247-270

397 Hommersand MH, Fredericq S (1995) Sexual reproduction and cystocarp development.

398 In: Cole KM, Sheath RG (eds) Biology of the Red Algae. Cambridge University Press,

399 New York, pp 305-345

400 Howarth R, Michaels A (2000) The measurement of primary production in aquatic

401 ecosystems. In: Sala OE, Jackson RB, Mooney HA, Howarth RW (eds) Methods in

402 ecosystem science, Springer-Verlag, New York, pp 74-85

403 Inskeep WP, Bloom PR (1985) Extinction coefficients of chlorophyll a and b in N,N-

404 dimethylformamide and 80\% acetone. Plant Physiol 77:483-485 
405 Kamiya M, Kawai H (2002) Dependence of the carposporophyte on the maternal

406 gametophyte in three ceramiacean algae (Rhodophyta), with respect to carposporophyte

407 development, spore production and germination success. Phycologia 41:107-115

408 Kain JM, Destombe C (1995) A review of the life history, reproduction and phenology of

409 Gracilaria. J App Phycol 7:269-281

410 Mathieson AC, Guo Z (1992) Patterns of fucoid reproductive biomass allocation. Br

411 Phycol J 27:37-41

412 McCourt RM (1985) Reproductive biomass allocation in three Sargassum species.

413 Oecologia 67:113-117

414 Meneses, I. 1996. Sources of morphological variation in populations of Gracilaria

415 chilensis Bird, McLachlan \& Oliviera of Chile. Revista Chilena de Historia Natural

$416 \quad 69: 35-44$

417 Obeso J (2002) The costs of reproduction in plants. New Phytol 155:321-348

418 Perrone C, Felicini GP (1988). Physiological ecology of Schottera nicaeensis

419 (Phyllophoraceae, Rhodophyta): functional significance of heterotrichy. Phycologia

$420 \quad 27: 347-354$

421 Pfister C (1992) Costs of Reproduction in an Intertidal Kelp: Patterns of Allocation and

422 Life History Consequences. Ecology 73:1586-1596

423 Rameau C, Gouyon PH (1991) Resource allocation to growth, reproduction and survival

424 in Gladiolus : The cost of male function. J Evol Biol 4:291-307

425 Reznick D, Nunney L, Tessier A (2000) Big houses, big cars, superfleas and the cost of

426 reproduction. Trends Ecol Evol 15:421-425 
427 Rydgren K, Økland RH (2003) Short-term costs of sexual reproduction in the clonal

428 Moss Hylocomium splendens. Bryologist 106:212-220

429 Sánchez I, Fernández C, Rico JM (2003) Distribution, abundance and phenology of two

430 species of Liagora (Nemaliales, Rhodophyta) in northern Spain. Phycologia 42:7-17

431 Santelices B (1990) Patterns of reproduction, dispersal and recruitment in seaweeds.

432 Oceanogr Mar Biol Annu Rev 28:177-276

433 Santelices B, Ugarte R (1990) Ecological differences among Chilean populations of

434 commercial Gracilaria. J App Phycol 2:17-26.

435 Santelices B, Varela D (1995) Regenerative capacity of Gracilaria fragments: effects of

436 size, reproductive state and position along the axis. J Appl Phycol 7:501-506

437 Stearns SC (1992) The Evolution of Life Histories. Oxford University Press, New York

438 Thornber CS (2006) Functional properties of the isomorphic biphasic algal life cycle.

439 Integr Comp Biol 46:605-614

440 Vernet P, Harper JL (1980) The costs of sex in seaweeds. Biol J Linn Soc 13:129-138

441 Wheelwright N, Logan BA (2004) Previous-year reproduction reduces photosynthetic

442 capacity and slows lifetime growth in females of a neotropical tree. Proc Natl Acad Sci

443 USA 101:8051-8055

444 Yang RL, Zhou W, Shen SD, Wang GC, He LW, Pan GH (2012) Morphological and

445 photosynthetic variations in the process of spermatia formation from vegetative cells in

446 Porphyra yezoensis Ueda (Bangiales, Rhodophyta) and their responses to desiccation.

447 Planta 235:885-893 
448 Yokoya YS, Necchi Jr O, Martins AP, Gonzalez SF, Plastino EM (2007) Growth

449 responses and photosynthetic characteristics of wild and phycoerythrin-deficient strains

450 of Hypnea musciformis (Rhodophyta). J Appl Phycol 19:197-205

451 Zhang X, van de Meer JP (1988) A genetic study on Gracilaria sjoestedtii. Can J Bot

$452 \quad 66: 2022-2026$

453 Zou DH, Gao KS, Ruan ZX (2006) Seasonal pattern of reproduction of Hizikia fusiformis

454 (Sargassaceae, Phaeophyta) from Nanao Island, Shantou, China. J Appl Phycol 18:195-

455201

456 Zou D, Gao K, Chen W (2011) Photosynthetic carbon acquisition in Sargassum

457 henslowianum (Fucales, Phaeophyta), with special reference to the comparison between

458 the vegetative and reproductive tissues. Photosynth Res 107:159-168

459 
460 Figure 1: Comparison between reproductive and vegetative fronds of female

461 gametophytes, male gametophytes and tetrasporophytes for: Chl a concentration (A), PE

462 concentration (B), PC concentration (C), net productivity (D), respiration (E), survival of

$4631 \mathrm{~cm}$ length segments after 50 days $(\mathrm{F})$ and growth, represented as the number of new

464 apices generated by the $1 \mathrm{~cm}$ length segments after 50 days $(\mathrm{G})$. Error bars indicate

465 standard error of the mean and significant differences are represented by different letters

466 (HSD tests, $p<0.05)$.

467 